\title{
EFFECT OF SURFACE STRUCTURE OF PLATINUM SINGLE CRYSTAL ELECTRODES ON THE ELECTROCHEMICAL REDUCTION OF $\mathrm{CO}_{2}$ IN METHANOL-WATER MIXTURES
}

Betzhy Cardenas, Victor Climent and Juan M. Feliu

Instituto Universitario de Electroquímica, Universidad de Alicante, Ap 90, E03080, Alicante, Spain.

Abstract: The reduction of $\mathrm{CO}_{2}$ on platinum single crystal electrodes has been investigated in methanol/water mixtures. The reaction is sensitive to the crystallographic structure of the surface, with the (111) triangular arrangement of atoms being the most active site. Use of stepped surfaces revealed that long range order has little effect on the reaction rate. On the other hand, the (100) site is the less active. The combination of the results of a voltammetric study using different scan rate and the use of a hanging meniscus rotating disk electrode configuration with different rotation speeds suggests the reaction rate is limited by a chemical step at large overvoltages. The nature of this chemical step is uncertain but different possibilities are discussed. The Tafel slope suggests that the rate determining step is the first electron transfer at low overvoltages while at high overvoltages the rate of the first chemical step limits the rate of $\mathrm{CO}_{2}$ reduction.

Keywords: $\mathrm{CO}_{2}$ reduction, platinum single crystal electrode, methanol water mixtures, cyclic voltammetry, hanging meniscus rotating disk electrode, FTIRRAS spectroscopy. 


\section{Introduction}

Over the last decades, tremendous environmental challenges have emerged as a consequence of the global warming phenomena caused by the emission of greenhouse gases such as $\mathrm{CO}_{2}, \mathrm{~N}_{2} \mathrm{O}$, and $\mathrm{CH}_{4}$. With the aim to alleviate this problem, different approaches have been developed for $\mathrm{CO}_{2}$ reactivation. $\mathrm{CO}_{2}$ can be transformed by biochemical, photochemical, and electrochemical conversion [1-3] and stored as various forms of hydrocarbon compounds. The electrochemical reduction of $\mathrm{CO}_{2}$ is considered a "clean" alternative, becoming an environmentally attractive technology [4-6]. For this reason, the electrochemical reduction of carbon dioxide has been extensively studied in recent decades. In these studies, it is often emphasized the convenience of obtaining products with high added value, such as hydrocarbon fuels [1, 7-9].

In general, the electrochemical reduction of $\mathrm{CO}_{2}$ depends on several variables, such as chemical nature of the working electrode, nature and concentration of the electrolyte, $\mathrm{pH}, \mathrm{CO}_{2}$ concentration, and purity of the reactants [10]. Various metal electrocatalysts have been screened experimentally [11-14] and analyzed computationally $[15,16]$ to rationalize their activity and selectivity for $\mathrm{CO}_{2}$ reduction. In this regards, the correlation between adsorption energy of different intermediates has been pointed out as the origin of the difficulty in the catalysis of this reaction [17-19]. Theoretically, $\mathrm{CO}_{2}$ can be reduced in an aqueous solution to form carbon monoxide, formic acid, methane and other hydrocarbons [20, 21].

In aqueous solution, there is a competition between $\mathrm{CO}_{2}$ reduction and $\mathrm{H}_{2}$ evolution because the formal potential for those reactions are quite close to each other. There are several ways to minimize this problem, including choosing electrode materials with high overpotential for $\mathrm{H}_{2}$ evolution, such as $\mathrm{Sn}, \ln , \mathrm{Bi}$, $\mathrm{Sb}, \mathrm{Cd}, \mathrm{Zn}, \mathrm{Pb}, \mathrm{Ga}$ and $\mathrm{C}$; choosing materials with higher affinities for $\mathrm{CO}_{2}$; operating under high $\mathrm{CO}_{2}$ pressures to increase the amount of dissolved $\mathrm{CO}_{2}$ and using non-aqueous solvents.

In fact, the use of non-aqueous solvents in the electroreduction of $\mathrm{CO}_{2}$ has several advantages, one of them being the increased solubility as compared with water. A variety of non-aqueous solvents have been studied with this purpose 
[22-27], such as acetonitrile, N,N' dimethylformamide (DMF), methanol, propylene carbonate ( $\operatorname{PrC})$ and dimethyl sulfoxide (DMSO).

Studies in aqueous solutions have demonstrated that $\mathrm{CO}_{2}$ reduction is a reaction sensitive to the crystallographic structure of the electrode surface [28-32]. In this sense, electrochemical studies with $\mathrm{CO}_{2}$ using well defined single crystal electrode surfaces have an additional academic value in the understanding of the relationship between electrode structure and reactivity. $\mathrm{CO}_{2}$ is a small molecule that allows a detailed analysis of its reactivity, not possible with larger and more complex molecules. While $\mathrm{CO}_{2}$ reduction in non-aqueous solvents has been extensively studied using a variety of different polycrystalline electrode materials [27, 33-41], the number of studies with well-defined electrode surfaces is much scarcer [42-44]. For this reason, and considering the high solubility of $\mathrm{CO}_{2}$ in methanol [45], we address in this work, the study of the electroreduction of $\mathrm{CO}_{2}$ in methanol/water mixtures using platinum single crystal electrodes.

\section{Experimental}

\section{Chemicals}

$\mathrm{LiClO}_{4}$ for analysis from Merck, Methanol from Merck and ultrapure water (18.2 $\mathrm{M} \Omega \mathrm{cm})$, from an Elga PURELAB Ultra water purification system were used for the preparation of the electrolyte solutions. Solutions were saturated with $\mathrm{CO}_{2}$ by bubbling the gas ( $\geq 99.998$ from Air Liquide) for at least $10 \mathrm{~min}$.

\section{Platinum single crystal electrodes}

Platinum single crystal electrodes with well-defined surfaces were prepared by melting and subsequent slow crystallization of a $99.999 \%$ platinum wire. The resulting single crystal beads were oriented, cut and polished following the procedure described in Refs [46, 47]. The reactivity for $\mathrm{CO}_{2}$ reduction has been investigated for the three basal planes of platinum $\operatorname{Pt}\left(\begin{array}{lll}1 & 1 & 1\end{array}\right), \operatorname{Pt}\left(\begin{array}{lll}1 & 1 & 0\end{array}\right)$ and $\operatorname{Pt}\left(\begin{array}{ll}1 & 0\end{array}\right.$ $0)$ and stepped surfaces with complex structures between the $\{100\}$ and $\{111\}$ poles, namely, $\operatorname{Pt}(\mathrm{S})[\mathrm{n}(111) \times(100)]$ and $\operatorname{Pt}(\mathrm{S})[\mathrm{n}(100) \times(111)]$. In all cases, the 
geometric surface area was measured with a microscope. Throughout this paper, all current densities are referred to this geometric surface area. Hydrogen adsorption charges, measured in acidic aqueous solutions show that, for these electrodes, the surface roughness is near unity.

\section{Cyclic Voltammetry}

The experiments were performed using a conventional electrochemical cell composed of three electrodes. Before each experiment, the single crystal working electrode was annealed and cooled down in hydrogen + argon reductive atmosphere (both N-50, Air Liquide) as described in [48] and protected with ultrapure water before transferring to the electrochemical cell. The counter electrode was a platinum wire and the potentials were measured against an $\mathrm{Ag} / \mathrm{AgCl} / \mathrm{KCl}(3 \mathrm{M})$ electrode connected to the cell through a Luggin capillary. The electrode potential was controlled using an EG\&G PARC 175 signal generator in combination with an eDAQ EA161 potentiostat and currents were recorded using an eDAQ e-corder ED401 recording system. The supporting electrolyte was composed of a mixture of $90 \%$ of methanol and $10 \%$ of $0.1 \mathrm{M} \mathrm{LiClO}_{4}$ aqueous solutions; the electrolyte solution was purged with either $\mathrm{Ar}$ or $\mathrm{CO}_{2}$ for at least 10 min before each experiment.

\section{Infrared Spectroscopy}

In situ external reflection infrared experiments were carried out with a Nicolet 8700 (Thermo Scientific) spectrometer equipped with a MCT-A detector using ppolarized or s-polarized light, as noted, and with a spectral resolution of $8 \mathrm{~cm}^{-1}$. The glass spectroelectrochemical cell was equipped with a prismatic $\mathrm{CaF}_{2}$ window bevelled at $60^{\circ}$. The $\mathrm{Pt}(111)$ working electrode used in these experiments was ca. $4.5 \mathrm{~mm}$ in diameter and was prepared and treated before experiments in a similar way as the smaller samples used in the voltammetric experiments. The spectra are plotted in absorbance units $\left(-\log \left(R / R_{0}\right)\right)$ by referring the single beam reflectance spectrum collected at the sample potential $(R)$ to that collected at the reference potential $\left(R_{0}\right)$, which was chosen at $0.05 \mathrm{~V}$. To characterize the spectral contribution of species in solution, an ATR configuration was employed, using a 
ZnSe hemispherical window. In this case, no electrode was used, and therefore, no potential control was applied, since only solution species want to be detected. After recording a reference spectrum with only the electrolyte solution, the desired analyte was added an the sample spectrum was collected. As before, the resulting spectrum is expressed in absorbance units.

\section{$\underline{\text { Results and discussion }}$}
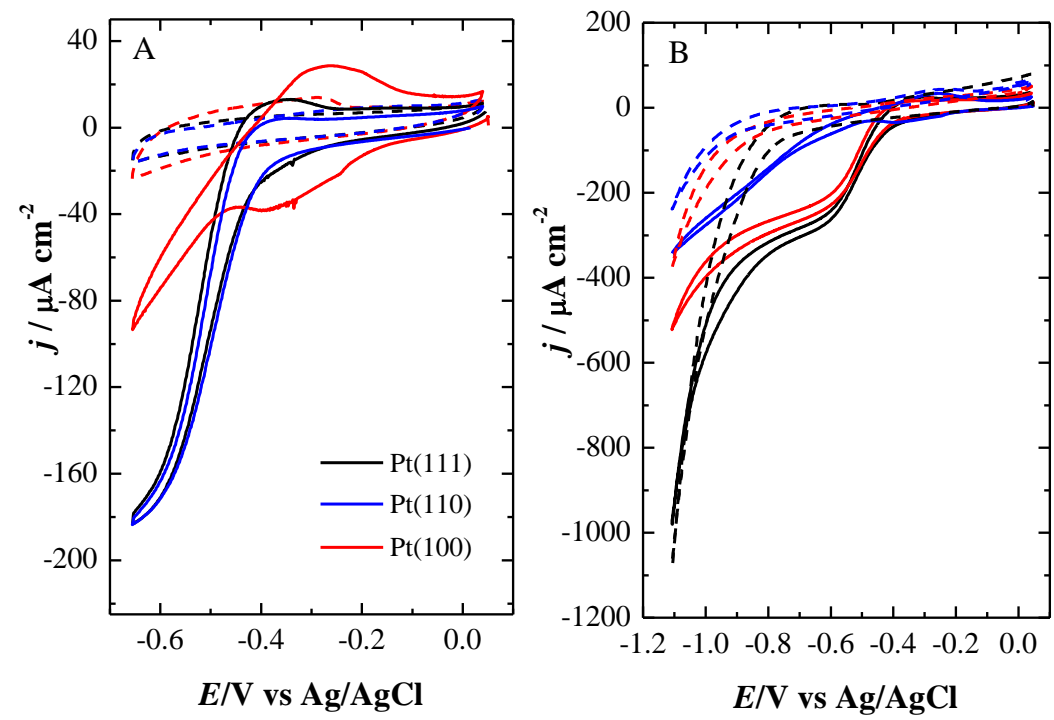

Figure 1.- Electrochemical behavior of Pt electrodes (black, Pt(111); blue, $\mathrm{Pt}(110)$ and red, $\mathrm{Pt}(100)$ ) in the absence (dashed lines) and presence (solid lines) of $\mathrm{CO}_{2}$. $A$ and $\mathrm{B}$ correspond to different potential ranges. Scan rate: 50 $\mathrm{mV} / \mathrm{s}$.

The effect of the crystallographic structure on the electroreduction of $\mathrm{CO}_{2}$ on platinum single crystal electrodes was investigated using cyclic voltammetry (CV). Figure 1 shows the result for the three basal planes. As can be observed in Fig 1 , no reduction wave is obtained in the absence of $\mathrm{CO}_{2}$. Voltammograms in this case show only a rather featureless double layer charging current. On the other hand, for the $\mathrm{CO}_{2}$ saturated solutions, a clear voltammetric wave is observed at potentials below $-0.4 \mathrm{~V}$. The lack of reduction currents in the absence of $\mathrm{CO}_{2}$ clearly demonstrates that the observed waves involve the participation of $\mathrm{CO}_{2}$ and are not just due to solvent decomposition. In this regards, special attention has been paid to compare the curves with and without $\mathrm{CO}_{2}$ at the same 
solution $\mathrm{pH}$ (solution of the blank was adjusted with the addition of a small amount of $\mathrm{HClO}_{4}$ ). This point is important since $\mathrm{CO}_{2}$ bubbling causes a non-negligible change in the $\mathrm{pH}$ of the solution (from ca. 6.8 to 4.5). Decrease of the lower limit of the potential cycling reveals that solvent decomposition starts at ca. $-0.8 \mathrm{~V}$, as clearly demonstrated in figure 1B. The voltammograms obtained for $\mathrm{Pt}(111)$ and $\mathrm{Pt}(110)$ are very similar. In both cases a sigmoidal wave is obtained with a similar value of the limiting current around $-250 \mathrm{\mu Acm}^{-2}$. On the other hand, a very distinctive voltammetric profile is obtained with $\mathrm{Pt}(100)$. In this case, the reduction current is much lower, starts at a slightly lower onset potential and no clear limiting value is observed even if the lower limit of potential is decreased to $-1.1 \mathrm{~V}$. Moreover, the main reduction wave is preceded by a couple of broad voltammetric peaks centered at $-0.39 /-0.27 \mathrm{~V}$, not observed in the voltammograms recorded for the other basal planes.

To further study the effect of the crystallographic structure, stepped electrode surfaces were used. These surfaces are obtained by cutting the single crystal at an intermediate angle between two basal planes. As a result, a composite surface is obtained with terraces of a given crystallographic orientation separated by monoatomic steps of the second orientation. Since the more distinctive result was obtained with the (100) surface, stepped surfaces with either (100) terraces or (100) steps were selected for this part of the study: $\operatorname{Pt}(S)[n(111) \times(100)]$ and $\mathrm{Pt}(\mathrm{S})[\mathrm{n}(100) \times(111)]$. The equivalence between Miller indices and the step and terrace structure of the surface is summarized in Table 1.

Table 1: Equivalence between Miller indices and the step and terrace structure (Lang, Joyner and Somorjai nomenclature) of the stepped surfaces employed in this work. $n$ represent the number of atomic rows on the terrace.

\begin{tabular}{|l|l|}
\hline Step and terrace structure & Miller indices \\
\hline $\operatorname{Pt}(\mathrm{S})[\mathrm{n}(111) \times(100)]$ & $\mathrm{Pt}(\mathrm{n}+1 \mathrm{n}-1 \mathrm{n}-1)$ \\
\hline $\operatorname{Pt}(\mathrm{S})[\mathrm{n}(100) \times(111)]$ & $\operatorname{Pt}(2 \mathrm{n}-111)$ \\
\hline
\end{tabular}


Figure 2 shows the effect of the introduction of (100) steps on the (111) surface. In this case, little effect is observed even for the most stepped surface (311), suggesting that the (111) triangular arrangement of atoms is the active site for this reaction without long range requirements. In this regards, we should recall that the (110) surface can indeed be considered as a combination of monoatomic (111) and (11 $\overline{1})$ steps and this can explain why (111) and (110) exhibit similar activity for $\mathrm{CO}_{2}$ reduction. Careful inspection of figure $2 \mathrm{~B}$ reveals that for the (311) surface, the sigmoidal shape disappears and the plateau observed at the lowest limit of potentials is substituted by a growing curve with an almost constant slope. Another interesting feature in the voltammogram of $\mathrm{Pt}(311)$ is the observation of the development of the redox couple at higher potentials characteristic of the $\operatorname{Pt}(100)$ surface.
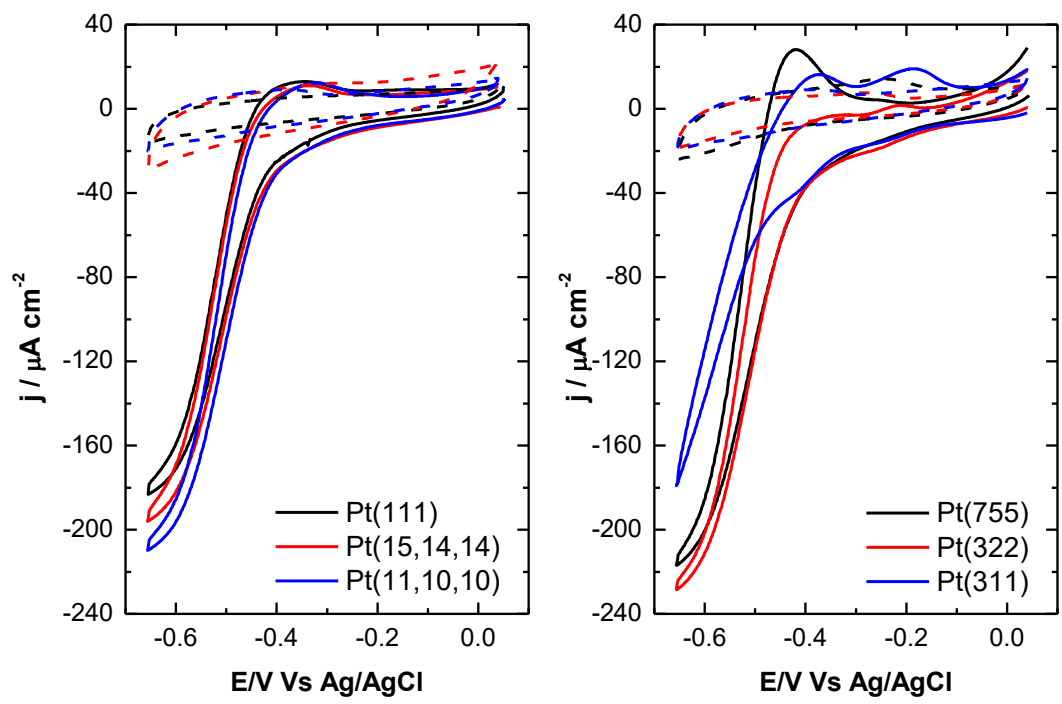

Figure 2.- Electrochemical behavior of $\operatorname{Pt}(\mathrm{S})[\mathrm{n}(111) \times(100)]=\operatorname{Pt}(\mathrm{n}+1, \mathrm{n}-1, \mathrm{n}-1)$ stepped surfaces in the presence of $\mathrm{CO}_{2}$. Scan rate: $50 \mathrm{mV} / \mathrm{s}$

Figure 3A shows the result of the introduction of (111) steps on the (100) surface. As for the basal planes, the blank voltammograms in the absence of $\mathrm{CO}_{2}$ show very small currents in this potential range. In this case, the reduction current significantly increases with the introduction of the steps, reinforcing the idea that the most active site for $\mathrm{CO}_{2}$ reduction is the (111) step even if these are isolated 
sites, such as the limiting case of $\mathrm{Pt}(110)$. Figure 3B shows a plot of the maximum reduction current (absolute value) measured at the lowest limit of the potential scan as a function of the step density. For this series of stepped surfaces, the step density is given by[49]:

$$
N=\frac{1}{d(n-1 / 2)}
$$

with $d$ being the atomic diameter of platinum and $n$ the number of atomic rows in the terrace. A good correlation is observed between both magnitudes, supporting the above suggestions.
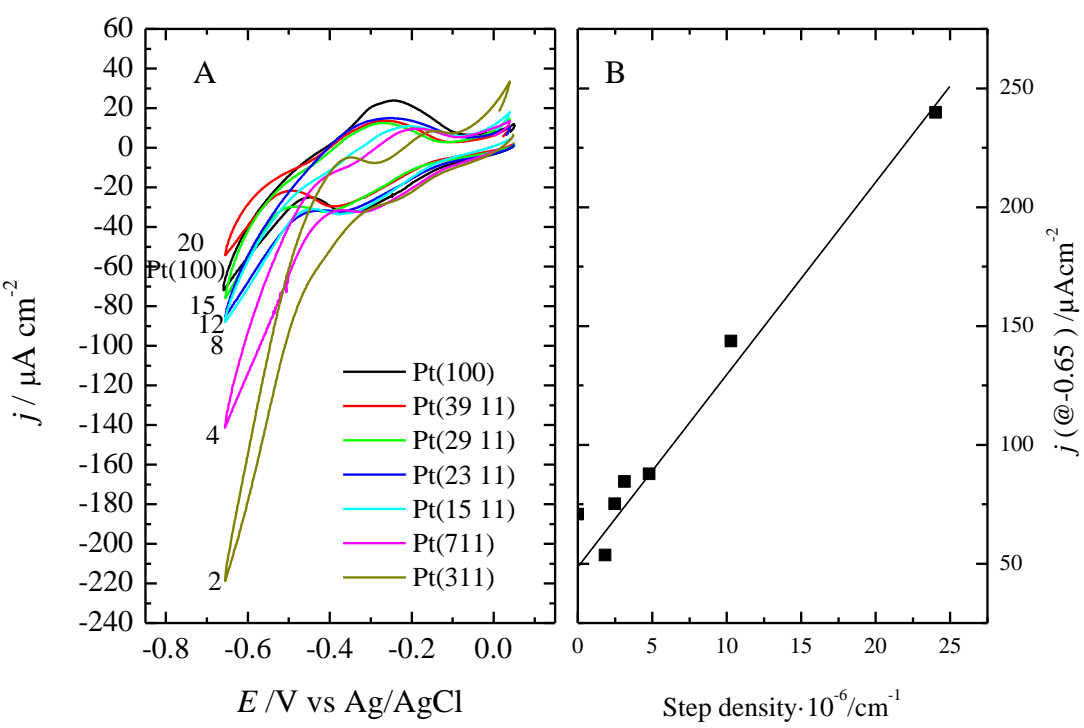

Figure 3.- Electrochemical behavior of $\operatorname{Pt}(\mathrm{S})[\mathrm{n}(100) \times(111)]=\operatorname{Pt}(2 \mathrm{n}-1,1,1)$ stepped surfaces in the presence of $\mathrm{CO}_{2}$. A) voltammetric scan measured in $\mathrm{CO}_{2}$ saturated solution. Scan rate:50 mV/s $\quad$ B) Plot of the current density at the lowest limit of the potential scan $(-0.65 \mathrm{~V})$ as a function of the step density.

Among the different products that have been reported for $\mathrm{CO}_{2}$ reduction on platinum electrodes, $\mathrm{CO}$ is the most common. In addition, methanol is well known to decompose on platinum surfaces to form adsorbed $\mathrm{CO}$, which constitutes a poisoning species that blocks the surface and decreases its catalytic activity. With this in mind, and in order to test the presence of adsorbed $\mathrm{CO}$ on the surface, the $\mathrm{CO}_{2}$ reduction experiment was repeated in the presence of dissolved $\mathrm{CO}$ gas. 
Figure 4 shows the results of this experiment. Curve a) was recorded, as before, on a $\mathrm{CO}_{2}$ saturated solution. To record curve b) $\mathrm{CO}$ was bubbled through the electrolytic solution for $10 \mathrm{~min}$ and then the potential was scanned negatively. Similarly, curve c) was recorded after bubbling a mixture of $\mathrm{CO}_{2} / \mathrm{CO}(90 / 10$ $\mathrm{scc} / \mathrm{m}$ ) for $10 \mathrm{~min}$. Clearly, introduction of $\mathrm{CO}$ significantly decreases the rate of $\mathrm{CO}_{2}$ reduction, as observed for curve $\mathrm{c}$ ), indicating that the surface has been blocked as a consequence of $\mathrm{CO}$ adsorption [28]. In turn, this suggests that adsorbed $\mathrm{CO}$ is formed at much lesser extent during $\mathrm{CO}_{2}$ reduction or as a consequence of methanol decomposition.

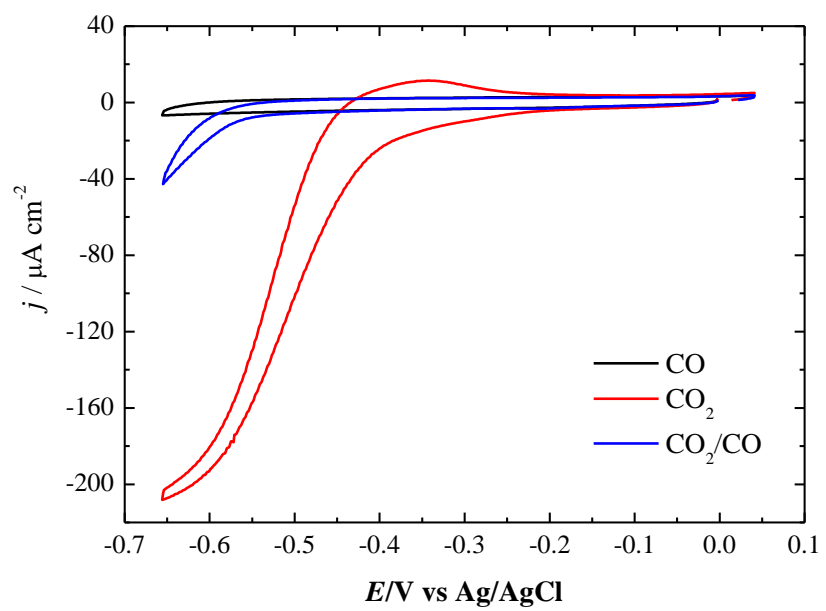

Figure 4.- Effect of $\mathrm{CO}$ in the Electrochemical behavior of $\mathrm{Pt}(111)$ electrode

To obtain further information about the mechanism of $\mathrm{CO}_{2}$ reduction, the dependence of the voltammetric wave on the scan rate was investigated. Figure 5 shows the cyclic voltammograms of $\mathrm{CO}_{2}$ reduction on different platinum electrodes at different scan rates. For $\mathrm{Pt}(111)$ and $\mathrm{Pt}(110)$ where a clear reduction wave is observed at low scan rate, only an increase of the double layer current is observed while the current in the reduction wave is maintained essentially unchanged. This is a clear indication that the plateau achieved at low potentials is not due to transport limitation. Moreover, a new peak appears in the anodic scan at $-0.35 \mathrm{~V}$ when the scan rate is increased. For Pt(100), the redox couple that precedes the onset of $\mathrm{CO}_{2}$ reduction becomes more and more irreversible (asymmetric) when the scan rate is increased, overlapping with the main $\mathrm{CO}_{2}$ reduction current. 


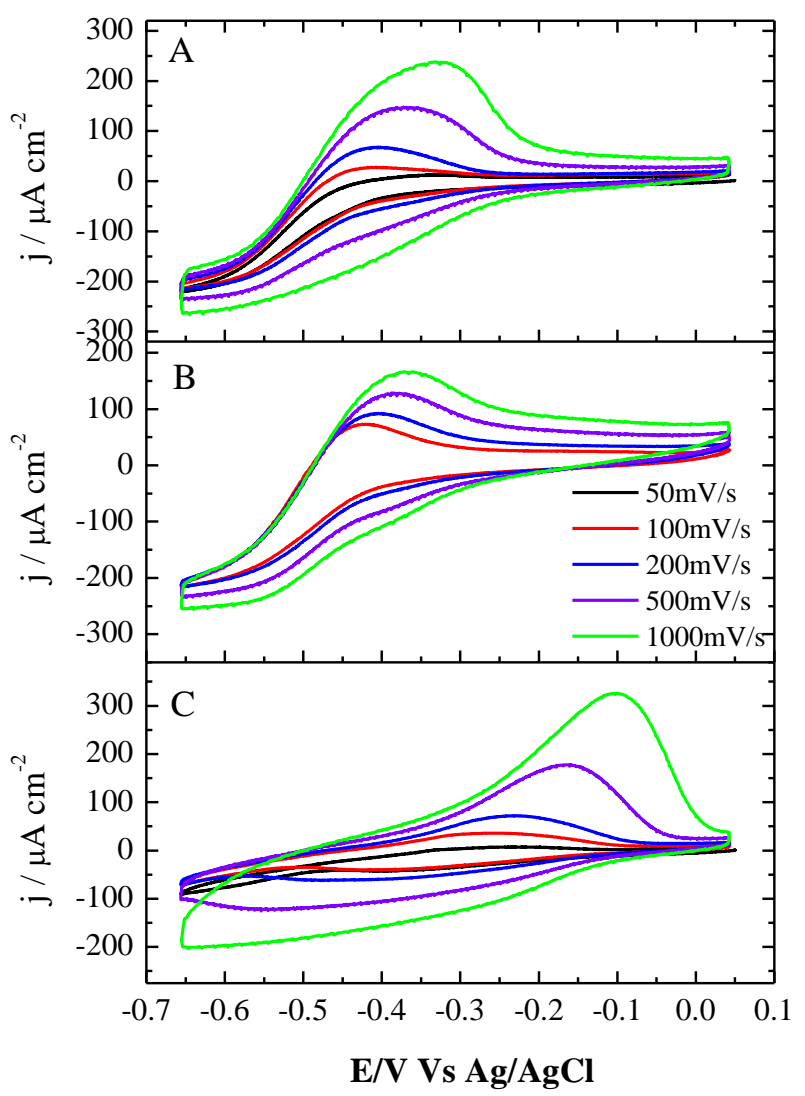

Figure 5.- Electrochemical behavior of Pt electrodes. Solution composition is $0.1 \mathrm{MLiClO}_{4}$ in $\mathrm{MeOH} / \mathrm{H}_{2} \mathrm{O}(90 / 10)$ for different scan rates, as indicated in the figure. A)Pt(111), B)Pt(110), C)Pt(100).

The anodic current in the positive scan could be due to the reoxidation of an intermediate product that is formed in the low potential range. This peak is not observed at low scan rates and increases when the scan rate is increased. One possible explanation for this observation is that the formation of this intermediate in the reduction wave is followed by a chemical reaction that reduces its concentration. The final product formed after this chemical reaction would not be reoxidized in the investigated potential window, and only the intermediate would be reoxidised. This would explain the decrease of the peak at low scan rate, where the long time staying at low potentials gives enough time for the disappearance of the intermediate through the chemical reaction. Alternatively, this process could be due to a pseudocapacitive current increasing linearly with the scan rate. In order to distinguish between both possibilities, some experiments were done in a hanging meniscus rotating configuration. Under 
these conditions, the rotation generates convective flux that removes the products of the reduction, therefore eliminating the possibility of their reoxidation in the positive sweep. The results recorded at different rotation speed with a scan rate of $200 \mathrm{mV} / \mathrm{s}$ are shown in figure 6. For $\mathrm{Pt}(111)$ and $\mathrm{Pt}(110)$, the positive peak is clearly seen at $-0.35 \mathrm{~V}$ in the voltammogram recorded without rotation, in accordance with the results of figure 5. However, as soon as the electrode is rotated, the convection decreases the magnitude of this peak, demonstrating that it is due to the reoxidation of a product formed in the negative scan and not to pseudocapacitive currents. Therefore, this observation supports the hypothesis of the existence of a chemical step following the main reduction wave.

Another interesting observation of the hydrodynamic experiments reported in figure 6 is that the limiting current at negative potentials does not increase with the rotation rate, supporting the idea that this current is not limited by diffusion. The existence of a chemical step before the first electron transfer could be the reason for the limiting current achieved at large overvoltages, in accordance with the effect reported above for both the rotation and the scan rate.

For $\mathrm{Pt}(100)$ a redox couple is observed around $-0.35 \mathrm{~V}$ that exhibits a very different behavior in comparison with the peak just described above for the other two basal planes. For $\mathrm{Pt}(111)$ and $\mathrm{Pt}(110)$ the peak is observed only in the positive scan at high scan rates and disappears when the electrode is rotated. For $\mathrm{Pt}(100)$ the peak in the cathodic scan is associated with a clear peak in the negative scan before the onset of $\mathrm{CO}_{2}$ reduction and maintains its magnitude regardless of the rotation rate. This suggests that the peak is due to an adsorption process, not controlled by diffusion. A voltammetric peak, although smaller, is also observed in the absence of $\mathrm{CO}_{2}$ (see dashed line in figure 1), suggesting that this redox couple could be due to hydrogen adsorption on (100) sites. The change after $\mathrm{CO}_{2}$ introduction could indicate an interaction between adsorbed hydrogen and $\mathrm{CO}_{2}$ or its reduction products. 


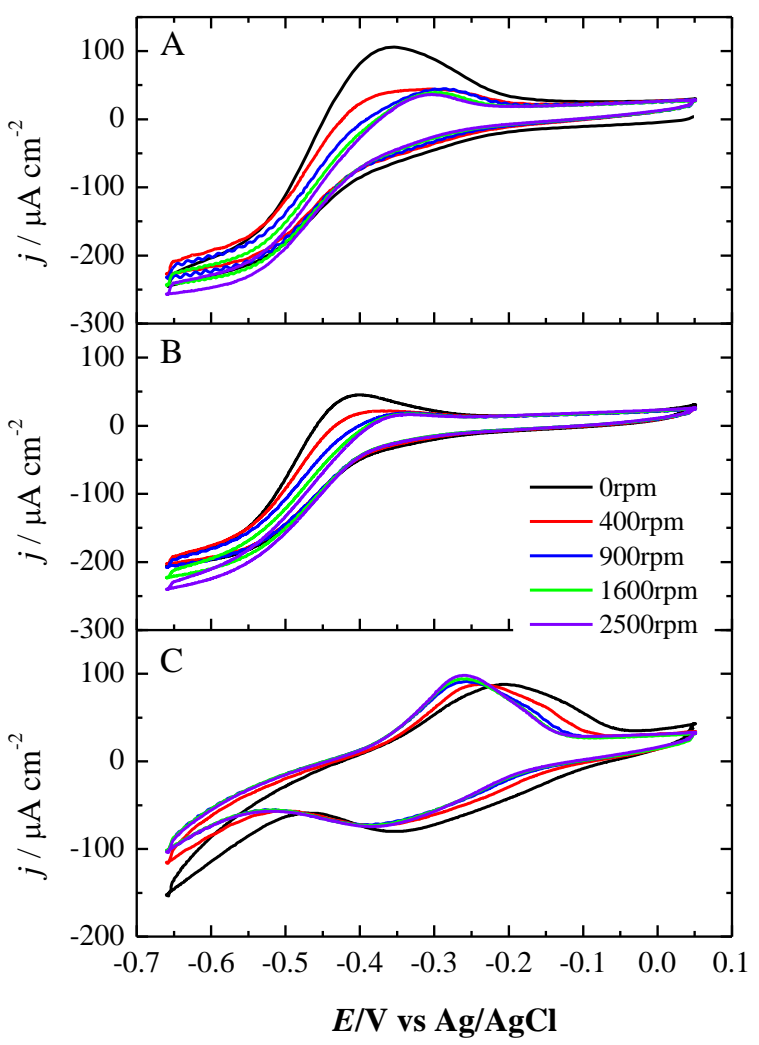

Figure 6.- Effect of the rotation rates in the electrochemical behavior of $\mathrm{Pt}$ electrodes. Rotation speed is indicated in the figure. Solution composition is $0.1 \mathrm{M} \mathrm{LiClO}_{4}$ in $\mathrm{MeOH} / \mathrm{H}_{2} \mathrm{O}(90 / 10)$; scan rate is $200 \mathrm{mV} / \mathrm{s}$. A) $\mathrm{Pt}(111)$, B) $\mathrm{Pt}(110), \mathrm{C}) \mathrm{Pt}(100)$.

In order to obtain more information about the mechanism for $\mathrm{CO}_{2}$ reduction, Tafel analysis was performed on the voltammetric current. For this analysis, the negative going sweep recorded at a low scan rate $(5 \mathrm{mV} / \mathrm{s})$ was chosen to avoid the interference of the anodic process. Figure 7 show the result on $\mathrm{Pt}(111)$. Although the curve soon deviate from linearity due to the limitation of the preceding chemical step, a short region with a Tafel slope of ca. $135 \mathrm{mV} /$ decade can be measured, confirming that, at low overvoltages, the first electron transfer is limiting the rate of the reduction. The deviation from the usual value of 120 $\mathrm{mV} / \mathrm{dec}$ is probably due to the interference of the initial chemical step or to a symmetry coefficient slightly lower than 0.5 . 


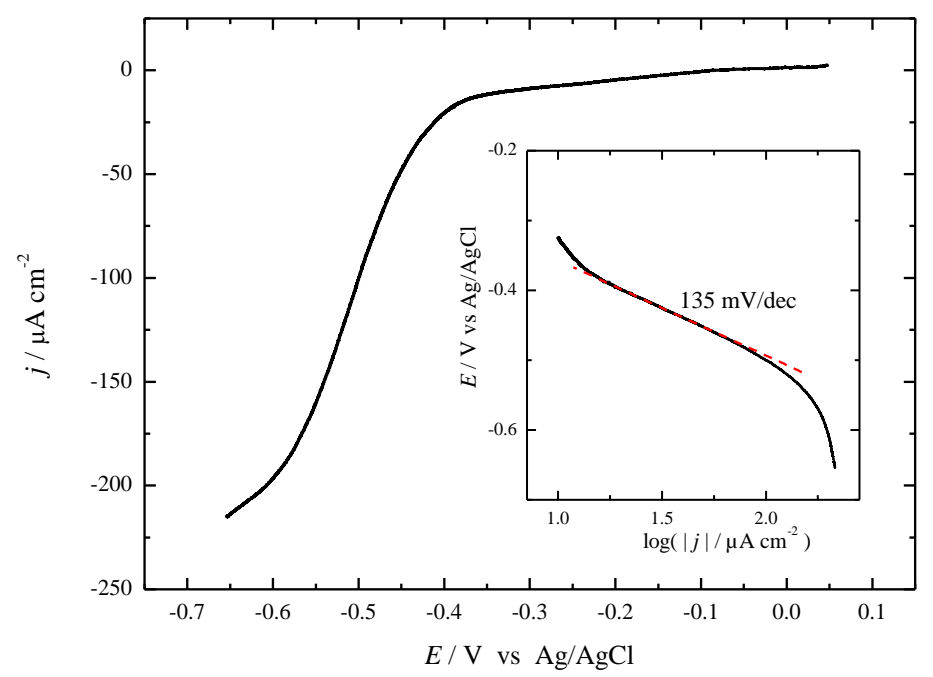

Figure 7.- A) linear sweep voltammogram for $\mathrm{CO}_{2}$ reduction on $\mathrm{Pt}(111)$. B) Tafel plot. Solution composition is $0.1 \mathrm{M} \mathrm{LiClO}_{4}$ in $\mathrm{MeOH} / \mathrm{H}_{2} \mathrm{O}(90 / 10)$. Scan rate: $5 \mathrm{mV} / \mathrm{s}$.

In an attempt to identify the products of $\mathrm{CO}_{2}$ reduction, we performed in situ FTIR external reflection measurements. Figure 8 shows the results of these experiments. In all cases, the electrode after flame annealing was contacted with the solution at an immersion potential equal to $0.05 \mathrm{~V}$ and a reference spectrum was acquired at this potential. Then the electrode potential was decreased stepwise at increments of $-50 \mathrm{mV}$ and a sample spectrum was acquired at each potential. Figure 8 shows only the final spectrum at the more negative potential limit $(-0.65 \mathrm{~V})$ for the three basal planes. Negative bands at $2340 \mathrm{~cm}^{-1}$ are observed in all cases, signaling the consumption of $\mathrm{CO}_{2}$. In addition, positive bands are observed at $1310 \mathrm{~cm}^{-1}$ that indicate the formation of $\mathrm{HCO}_{3}$. Bicarbonate is formed in the reaction of $\mathrm{CO}_{2}$ with the $\mathrm{OH}^{-}$species formed during $\mathrm{CO}_{2}$ reduction and/or hydrogen evolution reaction. In other words, $\mathrm{pH}$ changes in the thin layer of electrolyte trapped between the electrode and the window displaces the reaction between $\mathrm{CO}_{2}$ and water towards the formation of $\mathrm{HCO}_{3}$. To characterize the spectral features of solution species, additional spectra were collected in an ATR configuration, using a ZnSe prism, with no electrode. After recording a reference spectrum with blank electrolyte, either bicarbonate or $\mathrm{CO}_{2}$ was added to the solution and a new sample spectrum was collected. The spectra collected after adding $\mathrm{HCO}_{3}{ }^{-}$confirms the assignation of the band at $1310 \mathrm{~cm}^{-1}$ 
to this species. Other bands around 2050 and $1800 \mathrm{~cm}^{-1}$ (see enlargement in figure $8 \mathrm{~B}$ ) signal the formation of adsorbed $\mathrm{CO}$ in linear and brigded configuration, respectively. Absence of these bands in the spectra collected with s-polarized light (figure $8 \mathrm{C}$ ) demonstrate that they correspond to adsorbed species. These bands have a bipolar shape, with a negative band at higher wavenumbers and a positive one at lower wavenumbers. This indicates that $\mathrm{CO}$ is already present at the reference spectrum and therefore, it is formed from methanol decomposition and not from $\mathrm{CO}_{2}$ reduction. The bipolar band results as a consequence of the red shift of the band as the electrode potential is decreased. In the case of $\mathrm{Pt}(100)$, a conversion of linear to bridge configuration as potential is decreased [50] results in the observation of a clear positive band at $1800 \mathrm{~cm}^{-}$ 1.

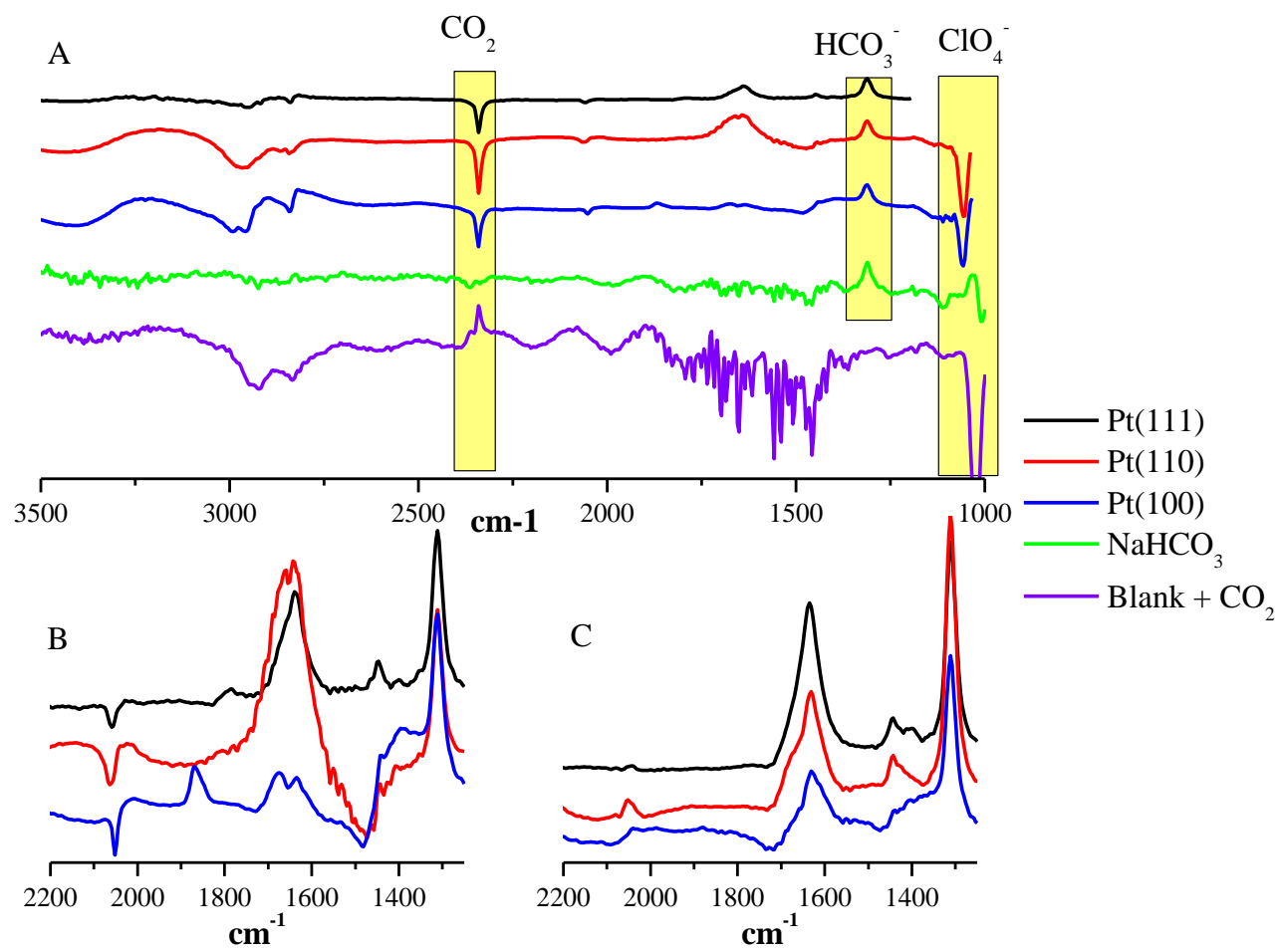

Figure 8: FTIR spectra of $\mathrm{CO}_{2}$ reduction at Pt electrodes at $-0.65 \mathrm{~V}(\mathrm{Vs} \mathrm{Ag} / \mathrm{AgCl})$ collected with either $p-(A, B)$ or s-polarised (C) light in $\mathrm{MeOH} / \mathrm{H}_{2} \mathrm{O} 90 / 10 \mathrm{LiClO}_{4}$ $0.1 \mathrm{M}$. Reference spectra taken at $0.05 \mathrm{~V}(\mathrm{Vs} \mathrm{Ag} / \mathrm{AgCl})$. The two spectra at the bottom of panel A) where obtained with ATR configuration using a ZnSe prism and in the absence of the electrode to characterize the spectral features of solution species. 


\section{Discussion:}

Previous results demonstrate that $\mathrm{CO}_{2}$ can be reduced on platinum electrodes in methanol / water mixtures. One of the most intriguing results is the invariance of the limiting current of the reduction wave for $\mathrm{Pt}(111)$ and $\mathrm{Pt}(110)$ as a function of the scan rate or the rotation rate. We suggested above that this is an indication that this limiting current is due to a chemical step that precedes the first electron transfer. Additionally, the dependence of the anodic peak on the scan rate suggests the existence of a second chemical step after the electron transfer, i.e., a CEC mechanism:

$A+B \rightleftharpoons A B$

$\mathrm{AB}+\mathrm{e} \rightleftharpoons \mathrm{C}+\mathrm{B}$

$\mathrm{C}+? \rightarrow$ Products

Unfortunately, the spectroscopic investigation did not allow the identification of any product or intermediate of the reaction that could shed some light to the nature of the different steps of the proposed mechanism. We also tried, without success, to identify by NMR the products of the reduction after prolonged electrolysis. The fact that the only product identified with FTIR is bicarbonate, that may result from local $\mathrm{pH}$ changes at the interphase, means that we cannot exclude the possibility that the observed voltammetric currents are due to $\mathrm{H}_{2}$ evolution. In this case, it is still unclear what is the role of $\mathrm{CO}_{2}$ in this process and how to reconcile this hypothesis with the scan rate and rotation rate dependence of the voltammograms. Figure 1 clearly shows that reduction currents in the absence of $\mathrm{CO}_{2}$ are much lower. Therefore, if we accept the possibility that, also in the presence of $\mathrm{CO}_{2}$, these are due to hydrogen evolution, $\mathrm{CO}_{2}$ presence has a clear enhancing effect on this process. This can be due to the buffering capacity of $\mathrm{CO}_{2}$ that can accept $\mathrm{OH}^{-}$to form bicarbonate. Under this hypothesis, in the absence of $\mathrm{CO}_{2}$, hydrogen evolution through $\mathrm{H}_{3} \mathrm{O}^{+}$reduction would be limited by the very low concentration of this species. Hydrogen evolution from water decomposition would take place at higher overvoltages. In the presence of $\mathrm{CO}_{2}$, protons would be supplied through the reaction: 
$\mathrm{CO}_{2}+\mathrm{H}_{2} \mathrm{O} \rightleftharpoons \mathrm{HCO}_{3}^{-}+\mathrm{H}^{+}$

therefore lowering the overvoltage for hydrogen evolution. This is a slow reaction [51] that could be at the origin of the invariance of the limiting reduction current with scan rate and rotation speed (the chemical step previously mentioned). Detailed simulations would be necessary to demonstrate if such mechanism could explain also the dependence with the scan rate of the anodic peak, which would be hydrogen oxidation under the present hypothesis.

An alternative hypothesis would be that observed reduction currents are indeed due to $\mathrm{CO}_{2}$ reduction. It has been proposed that $\mathrm{CO}_{2}$ interacts with the hydroxyl group of terminal alcohols to form an adduct, similar to carbonate [52]. A similar situation is well described for aqueous solutions of $\mathrm{CO}_{2}$, where the interaction with $\mathrm{H}_{2} \mathrm{O}$ forms $\mathrm{H}_{2} \mathrm{CO}_{3}$. Although this equilibrium is displaced in significant extent towards the dissociated products, a non-negligible amount of $\mathrm{H}_{2} \mathrm{CO}_{3}$ exists in aqueous solutions ( $\mathrm{K}=600)$ [51]. Formation of a similar adduct with the hydroxyl group is the explanation of the enhanced solubility of $\mathrm{CO}_{2}$ in alcohols [52]. Therefore, we can expect that formation of this adducts is more favorable in alcoholic than in aqueous solution. We can tentatively propose that formation of this adduct could be an activation step that would favors the following electron transfer. Rate of this step would be limiting at high overvoltages, resulting on the limiting reduction current observed in the voltammograms presented above. The electron transfer would limit the reduction current at low overvoltages, in accordance with the Tafel slope reported in figure 7. According to this, the mechanism will be:

$\mathrm{CO}_{2}+\mathrm{CH}_{3} \mathrm{OH} \rightleftharpoons \mathrm{HOCOOCH}_{3}$

$\mathrm{HOCOOCH}_{3}+\mathrm{e} \rightleftharpoons \mathrm{CO}_{2}{ }^{-}+\mathrm{CH}_{3} \mathrm{OH}$

$\mathrm{CO}_{2}^{-}+\ldots \rightarrow$ Products

Alternatively, we could think that the adduct is formed in solution in such extent that it needs to be dissociated before the electron transfer can proceed

$\mathrm{HOCOOCH}_{3} \rightleftharpoons \mathrm{CO}_{2}+\mathrm{CH}_{3} \mathrm{OH}$ 
$\mathrm{CO}_{2}+\mathrm{e} \rightleftharpoons \mathrm{CO}_{2}^{-}$

$\mathrm{CO}_{2}^{-}+\ldots \rightarrow$ Products

In this case, it would be the breaking of the adduct the limiting step at high overvoltages. We still have to explain the reason for the lack of detected products on the spectra collected after $\mathrm{CO}_{2}$ reduction. We cannot rule out that some products are not detected simply because they are formed at a concentration that is below the detection limit of the technique. Other possibility is that methanol is one of the products of $\mathrm{CO}_{2}$ reduction and therefore it cannot be distinguished from the solvent.

Unfortunately, with the present results it is not possible to discern between the different possibilities presented above. More work is in progress to clarify these questions.

\section{Conclusions}

The electroreduction of $\mathrm{CO}_{2}$ in Methanol/water mixtures has been investigated using Platinum single crystal electrodes. An interesting sensitivity to the crystallographic structure has been observed, with the activity following the order $(111) \sim(110)>(100)$. The study with stepped surfaces revealed that $(111)$ is the active site for this reaction without long range order requirements. The voltammetric results are compatible with a CEC mechanism under these conditions although the exact nature of the different steps is still unclear. The first electron transfer limits the rate of the reaction at low overvoltages, as deduced from the value of the Tafel slope. At high overvoltages, the rate of the chemical step is the one limiting the overall reaction rate. For $\mathrm{Pt}(100)$ a broad redox couple is observed before the onset of $\mathrm{CO}_{2}$ reduction that could be associated to an adsorption process on this surface.

Several hypothesis have been tentatively proposed to explain these results. One is that reduction currents are due to hydrogen evolution, which would be enhanced by the presence of $\mathrm{CO}_{2}$ in solution through a buffering effect. A second possibility is the formation of an adduct between $\mathrm{CO}_{2}$ and methanol as the origin 
for the chemical step limiting the rate of the reaction at large overvoltages. While $\mathrm{H}_{2}$ and bicarbonate formation cannot really be considered as a true $\mathrm{CO}_{2}$ reduction process, increase of reduction currents after $\mathrm{CO}_{2}$ addition is often considered sufficient proof that $\mathrm{CO}_{2}$ is being reduced. Careful consideration of the buffer effect of $\mathrm{CO}_{2}$ and the additional mechanistic clues discussed above together with a detailed mathematical simulation of the process are necessary to discern the different possibilities.

\section{Acknowledgments}

Financial support from MINECTO through projects CTQ2013-44083-P and PCIN2013-046 is greatly acknowledged. B. Cardenas also acknowledges the Generalitat Valenciana for the award of a Santiago Grisolia Grant.

\section{$\underline{\text { References }}$}

[1] R.J. Lim, M.S. Xie, M.A. Sk, J.M. Lee, A. Fisher, X. Wang, K.H. Lim, Catal. Today, 233 (2014) 169-180.

[2] H.R. Jhong, S.C. Ma, P.J.A. Kenis, Curr Opin Chem Eng, 2 (2013) 191-199.

[3] J. Wilcox, Carbon Capture, Springer, New York, 2012.

[4] J.L. Qiao, Y.Y. Liu, F. Hong, J.J. Zhang, Chem. Soc. Rev., 43 (2014) 631-675.

[5] D.A. Lowy, M. Jitaru, Electroreduction of Carbon Dioxide, in: K.-Y. Chan, C.-Y. Vanessa Li (Eds.) Electrochemically Enabled Sustainability, CRC Press, Boca Raton, 2014, pp. 1-54.

[6] J. Qiao, Y. Liu, J. Zhang, Electrochemical Reduction of Carbon Dioxide, in, CRC Press, Boca Raton, 2016.

[7] H.Y. Kim, I. Choi, S.H. Ahn, S.J. Hwang, S.J. Yoo, J. Han, J. Kim, H. Park, J.H. Jang, S.K. Kim, Int. J. Hydrogen Energy, 39 (2014) 16506-16512.

[8] F.L. Jia, X.X. Yu, L.Z. Zhang, J. Power Sources, 252 (2014) 85-89.

[9] D.H. Lim, J.H. Jo, D.Y. Shin, J. Wilcox, H.C. Ham, S.W. Nam, Nanoscale, 6 (2014) 5087-5092.

[10] S. Kaneco, H. Katsumata, T. Suzuki, K. Ohta, Energy Fuels, 20 (2006) 409-414.

[11] H. De Jesus-Cardona, C. del Moral, C.R. Cabrera, J. Electroanal. Chem., 513 (2001) 45-51.

[12] B. Innocent, D. Liaigre, D. Pasquier, F. Ropital, J.M. Leger, K.B. Kokoh, J. Appl. Electrochem., 39 (2009) 227-232.

[13] M. Jitaru, D.A. Lowy, M. Toma, B.C. Toma, L. Oniciu, J. Appl. Electrochem., 27 (1997) 875889.

[14] H. Noda, S. Ikeda, Y. Oda, K. Imai, M. Maeda, K. Ito, Bull. Chem. Soc. Jpn., 63 (1990) 24592462.

[15] A.A. Peterson, J.K. Norskov, Journal of Physical Chemistry Letters, 3 (2012) 251-258.

[16] W.J. Durand, A.A. Peterson, F. Studt, F. Abild-Pedersen, J.K. Norskov, Surf. Sci., 605 (2011) 1354-1359.

[17] C. Shi, H.A. Hansen, A.C. Lausche, J.K. Norskov, Phys. Chem. Chem. Phys., 16 (2014) 47204727.

[18] C. Shi, K. Chan, J.S. Yoo, J.K. Norskov, Org. Process Res. Dev., 20 (2016) 1424-1430.

[19] J.S. Yoo, R. Christensen, T. Vegge, J.K. Norskov, F. Studt, Chemsuschem, 9 (2016) 358-363. 
[20] E.E. Benson, C.P. Kubiak, A.J. Sathrum, J.M. Smieja, Chem. Soc. Rev., 38 (2009) 89-99.

[21] M. Jitaru, Journal of the University of Chemical Technology and Metallurgy, 42 (2007) 12.

[22] B. Eneau-Innocent, D. Pasquier, F. Ropital, J.M. Léger, K.B. Kokoh, Applied Catalysis B: Environmental, 98 (2010) 65-71.

[23] K. Ito, S. Ikeda, N. Yamauchi, T. lida, T. Takagi, Bull. Chem. Soc. Jpn., 58 (1985) 3027-3028.

[24] L.V. Haynes, D.T. Sawyer, Anal. Chem., 39 (1967) 332-\&.

[25] T. Saeki, K. Hashimoto, N. Kimura, K. Omata, A. Fujishima, J. Electroanal. Chem., 404 (1996) 299-302.

[26] Y.B. Vassiliev, V.S. Bagotzky, O.A. Khazova, N.A. Mayorova, J. Electroanal. Chem., 189 (1985) 295-309.

[27] B.R. Eggins, J. Mcneill, J. Electroanal. Chem., 148 (1983) 17-24.

[28] N. Hoshi, Y. Hori, Electrochim. Acta, 45 (2000) 4263-4270.

[29] N. Hoshi, E. Sato, Y. Hori, J. Electroanal. Chem., 540 (2003) 105-110.

[30] I. Kerbach, V. Climent, J.M. Feliu, Electrochim. Acta, 56 (2011) 4451-4456.

[31] A. Rodes, E. Pastor, T. Iwasita, J. Electroanal. Chem., 377 (1994) 215-225.

[32] S. Taguchi, A. Aramata, Electrochim. Acta, 39 (1994) 2533-2537.

[33] R. Ortiz, O.P. Marquez, J. Marquez, C. Gutierrez, J. Electroanal. Chem., 390 (1995) 99.

[34] S. Kaneco, K. liba, S.K. Suzuki, K. Ohta, T. Mizuno, J. Phys. Chem. B, 103 (1999) 7456-7460.

[35] S. Kaneco, K. liba, K. Ohta, T. Mizuno, J. Solid State Electrochem., 3 (1999) 424-428.

[36] S. Kaneco, R. Iwao, K. liba, S. Itoh, K. Ohta, T. Mizuno, Environ. Eng. Sci., 16 (1999) 131-137.

[37] S. Kaneco, R. Iwao, K. liba, K. Ohta, T. Mizuno, Energy, 23 (1998) 1107-1112.

[38] K. Ohta, M. Kawamoto, T. Mizuno, D.A. Lowy, J. Appl. Electrochem., 28 (1998) 717-724.

[39] A. Naitoh, K. Ohta, T. Mizuno, H. Yoshida, M. Sakai, H. Noda, Electrochim. Acta, 38 (1993) 2177-2179.

[40] S. Kaneco, H. Katsumata, T. Suzuki, K. Ohta, Electrochim. Acta, 51 (2006) 3316-3321.

[41] Y. Tomita, S. Teruya, O. Koga, Y. Hori, J. Electrochem. Soc., 147 (2000) 4164-4167.

[42] N. Hoshi, T. Murakami, Y. Tomita, Y. Hori, Electrochemistry, 67 (1999) 1144-1146.

[43] A.V. Rudnev, U.E. Zhumaev, A. Kuzume, S. Vesztergom, J. Furrer, P. Broekmann, T. Wandlowski, Electrochim. Acta, 189 (2016) 38-44.

[44] A.V. Rudnev, M.R. Ehrenburg, E.B. Molodkina, I.G. Botriakova, A.I. Danilov, T. Wandlowski, Electrocatalysis, 6 (2015) 42-50.

[45] P. Luhring, A. Schumpe, J. Chem. Eng. Data, 34 (1989) 250-252.

[46] J. Clavilier, D. Armand, S.G. Sun, M. Petit, J. Electroanal. Chem., 205 (1986) 267-277.

[47] C. Korzeniewski, V. Climent, J.M. Feliu, Electrochemistry at Platinum Single Crystal Electrodes, in: A.J. Bard, C. Zoski (Eds.) Electroanalytical Chemistry: A Series of Advances, Vol 24, vol. 24, 2012, pp. 75-169.

[48] J. Clavilier, K.E. Actii, M. Petit, A. Rodes, M.A. Zamakhchari, J. Electroanal. Chem., 295 (1990) 333-356.

[49] J.M. Feliu, E. Herrero, V. Climent, Electrocatalytic Properties of Stepped Surfaces, in: E. Santos, W. Schmickler (Eds.) Catalysis in Electrochemistry, John Wiley \& Sons, Inc., Hoboken, 2011, pp. 127-163.

[50] S.C. Chang, M.J. Weaver, J. Phys. Chem., 94 (1990) 5095.

[51] N.N. Greenwood, A. Earnshaw, Chemistry of the elements, 2nd ed., Butterworth Heinemann, 1998.

[52] O. Aschenbrenner, P. Styring, Energy Environ. Sci., 3 (2010) 1106-1113. 